\title{
Finding an optimal path with hospital information system using GIS- based Network analysis
}

\author{
MB SUSHMA, VEERA REDDY \\ Department of Civil Engineering \\ Kakatiya Institute of Technology and Science, Warangal \\ Warangal, Telengana-506015 \\ INDIA
}

\begin{abstract}
In the midst of the viral outbreak of the COVID-19 pandemic, the foremost important thing for every person is to have information about the health care facilities in their nearby locations. Along with it is also important to know the accurate route information to reach the health care unit. Especially in a country like India, with a high population rate, the transport network becomes complicated and massive. As the Indian government has started the process of unlocking in most parts of India, which is likely to increase the complication of finding the proper route to visit unfamiliar parts of the metropolis. In the pandemic situation, it becomes even important for the person to locate the specialized hospital and obtain its shortest path to reach in a minimum time period. This paper addresses the problem by evaluating the shortest path facility for finding the nearest emergency location from a defined user's location. The study uses a GIS-based map and Dijkstra's algorithm to identify the shortest route.
\end{abstract}

Keywords: - GIS, Shortest path analysis, Service area, Dijkstra's algorithm

Received: October 23, 2020. Revised: February 22, 2021. Accepted: February 24, 2021. Published: March 2, 2021.

\section{Introduction}

Eight months have been passed since the WHO declared a pandemic (March 11, 2020). During this period many studies have been conducted by the researcher on COVID-19. These studies have addressed the awareness on the pandemic situation, and covering the broader prospective of all the disciples including medicines, mathematics, social sciences, etc. This paper focuses on the geographical dimension to identify the optimal route network to the nearest hospital from the user's location with the use of GIS.

Transportation is the most critical and complex component of the urban development that plays a vital role in lives of the people. It also has a vast contribution in the development of the country's economy. Sustainable development of a region facilitates an efficient route planning and accessibility to desired service locations. Geographical Information System (GIS) tool helps to identify the fastest or the shortest way between those locations. GIS has a wide variant of applications such as site analysis for fire stations, petrol stations, finding optimal route for service stations, measurement of best feasible location for the health care centers. The entire road network of the study area is collected, and the road network database is developed in GIS. The shortest path problem is to detect the minimum cost path between the two defined termini. The cost can be determined in terms of monetary, travel time or with maximum benefit, based on the requirement of the problem.

In this paper, the study uses graph patterns to represent the routes/paths within the study area, consisting of set of vertices and edges. The model in this study finds the path with the lowest accumulated cost between the two adjacent termini. This approach allows the computation of paths with a fixed width. The lengths of the edges are defined by some weights such as distance or travel time, which are further used for evaluating the routes for the optimal or the shortest route. ArcGIS network analyst tool based on the network-based spatial analysis and Dijkstra's algorithm is used to determine the optimal route.

\section{Literature Review}

GIS has a wide application including the physical accessibility is various locations such as school, emergency services, petrol stations, tourist locations [1][2][3]. Many researchers have used network based spatial analysis tool for routing, travel directions, identify the facilities nearby and for service area analysis [4]. Stefanakis and Kavouras modelled the slope as a cost for finding the quickest and most significant path across the region [5]. The 
spatial analysis tool was to develop a health care facility for Joharbahru city in Malaysia [6]. In this an advance connectivity model was developed that represented the complex scenarios of multimodal transportation network. A mobile based navigation web application system was developed that basically design to identify the hinder factors (such as, hospitals, schools, residential areas, traffic lights another traffic factors) and develop a shortest path network [7]. The main aim of the study was to use the web GIS and GNSS technology with open source data and tools and combine it with the GPS module of the phone. This provided an intelligent vehicle navigation system [7]. A health care information system was also developed for China, that identified the technical solution for management of the health information system [8]. Rai et al. (2013) used the network analysis system to identify the optimal route between any two given termini [9]. The results of the study provided user the direction to travel on the identified path.

\section{Methodology}

The ArcGIS network analyst enables user to dynamically model the realistic network conditions, that includes turn restrictions, speed limits, height restrictions, and traffic conditions at various time period of the day. Network analysis is used for measuring the effective distance, rather than the Euclidian distance, between habitat patches. This method has been used in planning to assess the connectivity of existing or proposed reserves. GIS technology is an important tool for conducting this analysis. Typically, a resistance surface in raster format is the input to this model. This resistance surface is derived from one or more spatially explicit variables such as animal-habitat relationships distance to development or other avoided areas, topography, physical barriers such as fences, roads, or streams. GIS habitat layers in polygon or grid format are weighted according to the expected resistance encountered by an organism when moving across the surface and linear features are then merged with the weighted resistance surface.

The Dijkstra's algorithm determines the leastcost path from a source point to the destination [10]. It is a graph search algorithm that solves the unisource shortest path problem for a defined graph with non-negative edge costs. Dijkstra's algorithm is used to run from a single cell to all other cells, which has the cumulative value of cost to identify each cell along the minimum length path evolving from the start point. Aside from requiring that the destination be specified, the model uses Cost Path tool that requires two raster's derived from a cost distance tool (Note: cost is determined in terms of distance) the least-cost distance and back link raster. These raster's are created from the Cost Distance/Path Distance tools. The back-link grid is used to retrace the least costly route from the destination to the source over the path distance surface. The cost back link grid used to determine the path to return to a source via the least-cost path. For each cell in the back link grid, a value identifies the neighbor that is the next cell on the least accumulative cost path from the cell to a single or set of source cells. The back-link list is equivalent to the direction grid, used by the Dijkstra's algorithm to retrace the previous path. The pseudocode of the Dijkstra's algorithm is shown in Fig.1. It shows how the algorithm finds the minimum distance path for the given start (vertex) to the end point. The model uses the Weighted Overlay tool applies one of the most used approaches for overlay analysis to solve multi-criteria problems such as site selection and suitability models. In this tool each layer is assigned certain weightage as per the problem requirement. With this tool we can assign more or less weightage to the layer through which would provide more or less priority while route selction.

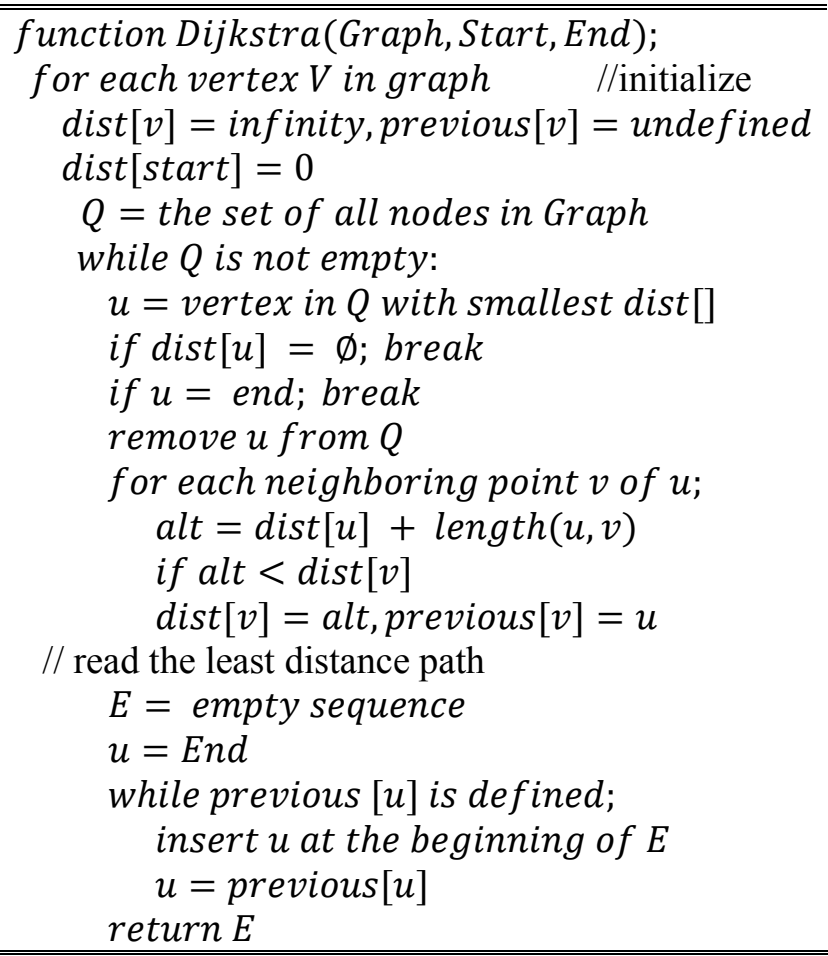

Fig 1: Pseudocode for Dijkstra's algorithm

\subsection{Derivation of Cost}

Let their be $N$ edges in the network. The cost for $N$ edges can be evaluated by using the costs required for between adjacent defined edges. Each $N$ edge of 
size $Z$ is defined as a single transition, which is composed of $z$-ordered pairs of indivisuals. Thus, the total cost can be derived by the summation of all the indivisual transition within the defined network. In this case, the cost of the edge is directly proportional to the size $z$, i.e., the distance between the two vertex. Let the cost associated for moving from one edge to another, i.e., $S_{1}$ and $E_{1}$ be $C\left(S_{1}, E_{1}\right)$. Thus the total cost can be mathematically formulated as shown in Equation 1.

$$
\begin{aligned}
& C\left(\left(S_{1}, S_{2}, S_{3}, \ldots \ldots S_{z}\right)\left(E_{1}, E_{2}, E_{3}, \ldots \ldots \ldots E_{z}\right)\right) \\
& =\sum_{i} C\left(S_{i}, E_{i}\right)
\end{aligned}
$$

\section{Case Study}

The study considers Warangal city part of the south Indian state of Telangana, shown in Fig.2. The city is located $17^{\circ} 58^{\prime} 8.04^{\prime \prime} \mathrm{N}$ latitude and $79^{\circ} 35^{\prime} 38.76^{\prime \prime}$ E longitude [11][12]. The total geographic area of the city is about $406.9 \mathrm{~km}^{2}$. By area it is the second largest city in the Telangana state. The population of the city is about 960,000 which also makes it second largest populated city in the state, after the state's capital, Hyderabad [13].

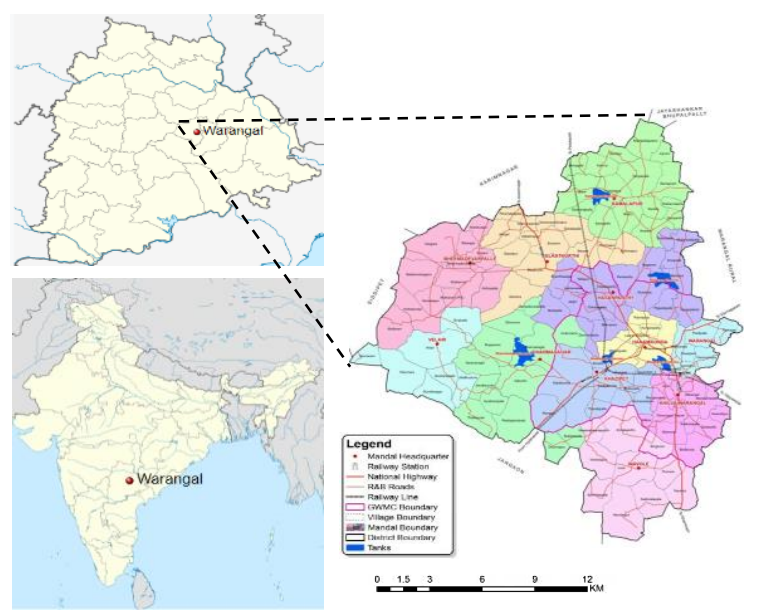

Fig 2: Geographical location of the Study area i.e., Warangal City

\subsection{Data Collection}

The hospital information such as the name, specialty of the hospital, site address of Warangal city was obtained from and is represented in Table 1[Note: Spl: Specialty; M: Multispecialty; MT: Maternity; E: Eye specialty; $C C$ : Childcare; $K \& C$ : Kidney childcare]. The geographical locations of these hospitals are shown in Fig.3. The attribute table was generated by considering all these information's within the GIS database. The geographical coordinates of the hospitals were obtained from the Google Earth map.
Table 1: Details of Hospitals in Warangal City

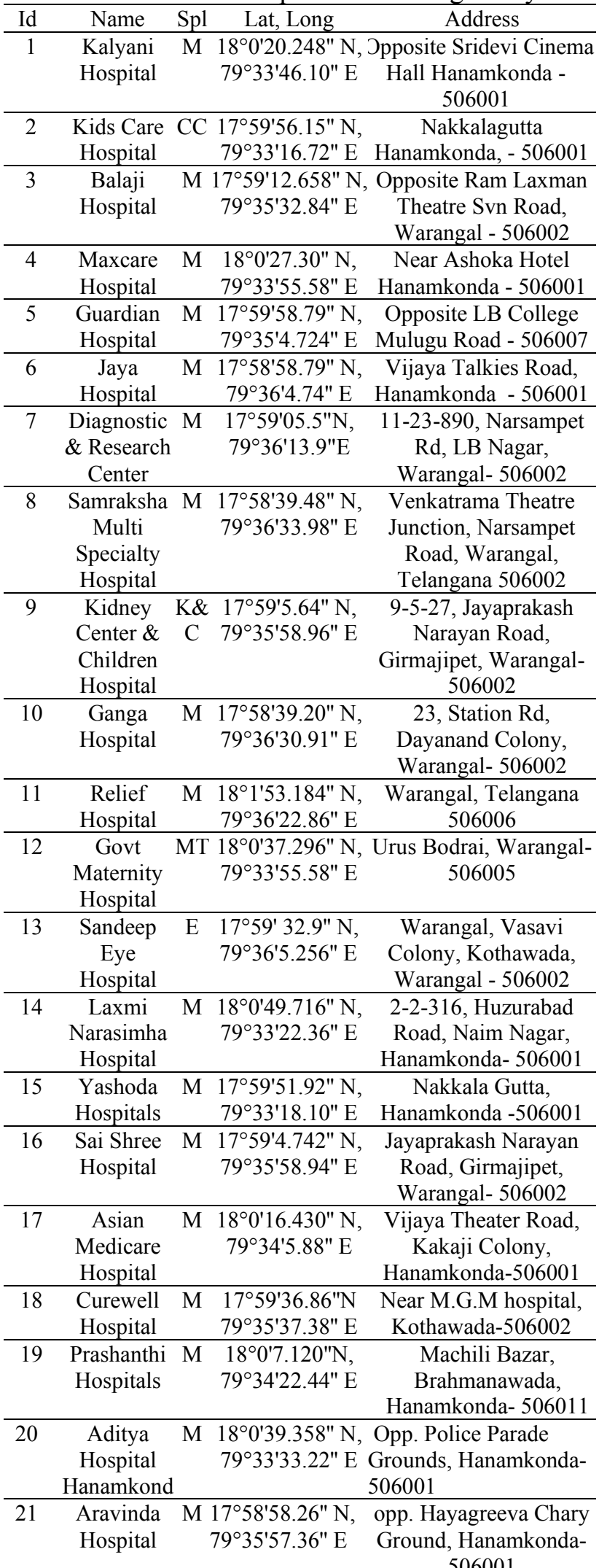

The spatial information required for the study includes road network and the hospitals information. The spatial data of the hospitals must include the service provided by each of the hospitals, so that the user can select as per the requirement. This spatial 
data for the city along with the road network information is obtained from DIVAGIS [14]. These information are stored in the GIS database in the form of attribute data.

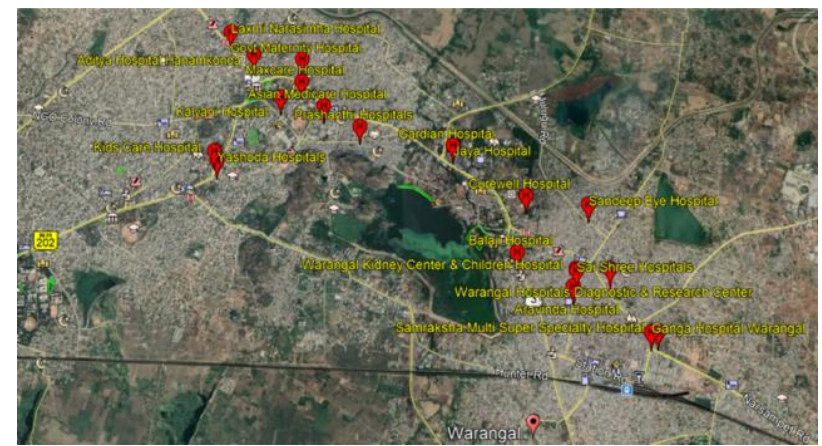

Fig 3: Geographical location of the Hospitals

\subsection{Experiment and Results}

The study assumes some assumption before evaluation of the shortest path. Such as, there is no traffic congestion in the study area, the calculations of the shortest path were purely based on the least distance between two vertex or location and also the condition of the road is not considered as such micro details of the study area was not readily available for the considered case study.

The model is initialized by providing the information of the study area, its road network and the hospital information. Then the location of the user is defined, i.e., the start point, along with the geographical coordinates of the selected hospital is defined, i.e., the end or the destination point. Then the least cost path is determined between the two defined termini. In this, the geographic modeling techniques typically converts the field view of geographic space to a discrete network approach. It is done by taking the available spatial data to build a cost based-network (i.e, cost in terms of distance) in the context of an existing network. Then each cell in the grid is allocated with a value that articulates the effort of passing over it, and that is determined in terms of length of the distance. In the next step, the model evaluates the overall cost of the cell, i.e., from the starting point and moving over the neighbouring cells. Pairs of these cells make the edges, which are weighted by the cells value. In this way the graph based algorithm, i.e, the Dijkstra's algorithm moves from one location to another till it reaches the end point. In every step, the model traces the links from the start point to the next connected point.

The shortest path is determined between the two user defined termini. The start point for the study is considered with geographic coordinates $17^{\circ} 58^{\prime} 53.33^{\prime \prime N}$ latitude and $79^{\circ} 34^{\prime} 48.06^{\prime \prime} \mathrm{E}$ longitude, and the end point, i.e., the location of the hospital with $17^{\circ} 59^{\prime} 4.742 " \mathrm{~N}$ latitude and 79³5'58.94"E longitude. The selected hospital is Sai Shree multispecialty Hospital. The Euclidean distance between the two termini is $2.11 \mathrm{~km}$ approximately. However, their exist many obligatory regions such as lake, steep elevations, etc., that prevents from having an idea path. Thus, the proposed method was used to determine the path between the two termini. The path obtained by the model is of $4.1 \mathrm{~km}$ and is represented in Fig.4. To verify the efficiency of the model, the obtained result was compared by obtaining the path between the same termini using the google navigation, shown in Fig. 5.

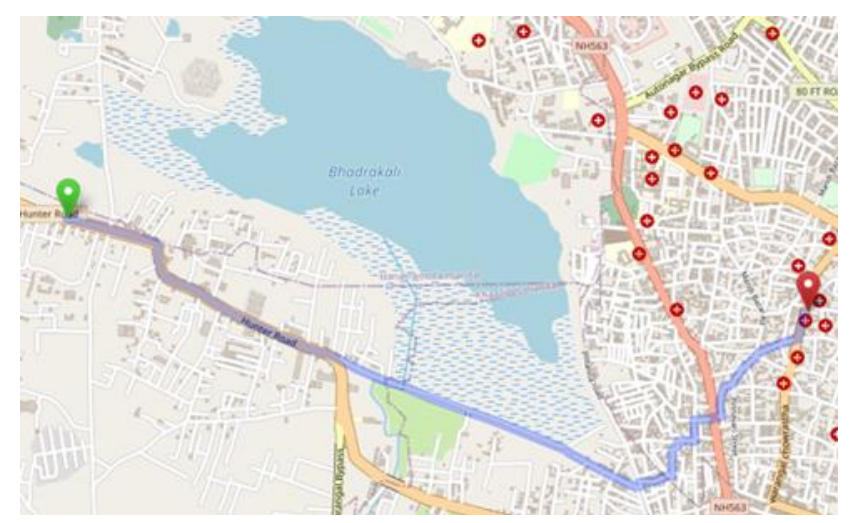

Fig 4: Shortest path from Start point to End point using Model

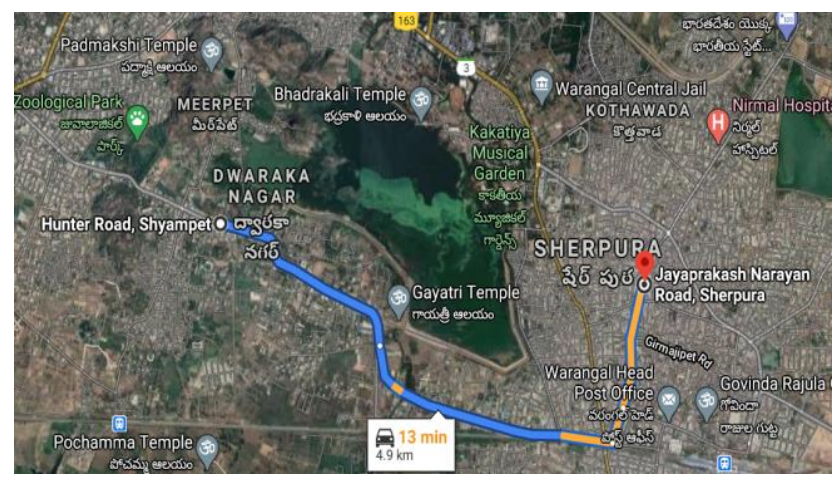

Fig 5: Shortest path from Start to End point using Google navigation

The path with minimum distance obtained by google navigation is $4.9 \mathrm{~km}$, which is higher than the solution obtained by the proposed model, i.e., $4.1 \mathrm{~km}$. Hence, it can be concluded that the proposed can efficiently obtain a shortest path between any two defined termini.

In this paper, the service area analysis is also conducted, where a region is created around the selected hospital point for determining other facilities within the region of $500 \mathrm{~m}$. The analysis 
showed that, other than the defined hospital, three other hospitals are present within its periphery of $500 \mathrm{~m}$. It is done, in case if the selected hospital is unavailable to provide the facility, then the user can approach other near by service provider. The area obtained using the service area analysis is represented in Fig.6. The names of those hospitals along with the distance of it from the selected hospital is given in Table 2 .

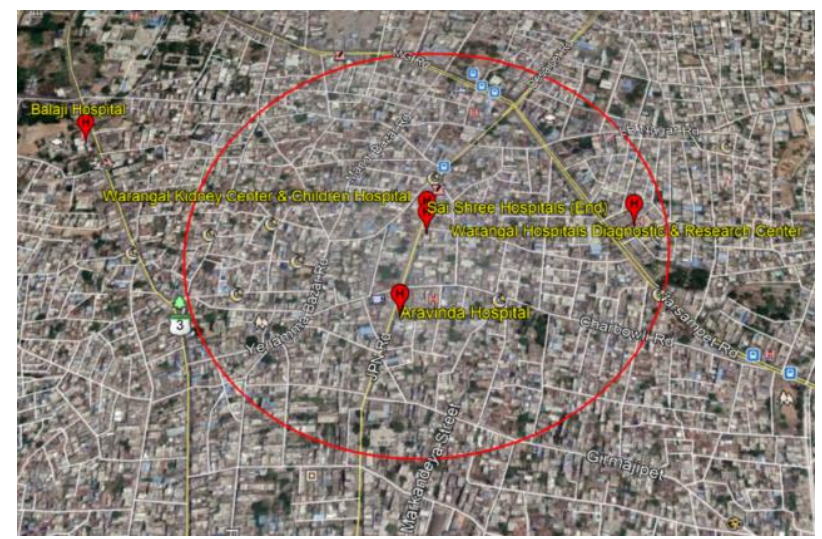

Fig 6: Area selected using Service Analysis

Table 2: Hospitals within service area

\begin{tabular}{llll}
\hline Id & Name & $\begin{array}{l}\text { Distance from } \\
\text { selected hospital }\end{array}$ & Spl \\
\hline 1 & $\begin{array}{l}\text { Warangal Kidney } \\
\text { Center \& Children }\end{array}$ & $0.030 \mathrm{~km}$ & $\mathrm{~K} \& \mathrm{C}$ \\
& Hospital & \\
\hline 2 & $\begin{array}{l}\text { Warangal Hospitals } \\
\text { Diagnostic \& }\end{array}$ & $0.44 \mathrm{Km}$ & $\mathrm{M}$ \\
& Research Center & & \\
\hline 3 & Aravinda Hospital & $0.20 \mathrm{Km}$ & $\mathrm{M}$ \\
\hline
\end{tabular}

\section{Conclusion}

This study finds the least-cost path i.e., path with minimum distance between the defined termini. The obtained path has a valid configuration that guarantees desirable path properties, such as avoiding self-intersections, forming loops within itself, passing over restricted areas, showing path of appropriate width from where a vehicle can pass. This method will be useful for the users to identify the shortest route to various service locations, especially finding the proper route to visit unfamiliar parts of the metropolis. It would help to reduce travel time and find the appropriate hospital location immediately.

Thus, for the defined termini, and given cost surface, the proposed model would operate with graph level construction defining its edges and vertex. This algorithm is independent and can be applied to all situation where the problem is to identify the least-cost or least distance path. In future, this study can be further improved by adding the real-time traffic information to the model and make it more efficient and realistic

\section{References:}

[1] Wilkinson, R. G. (1999). Income inequality, social cohesion, and health: clarifying the theory-a reply to Muntaner and Lynch. International Journal of health services, Vol. 29(3), pp. 525-543.

[2] Albert, D. P., Gesler, W. M., \& Horner, R. D. (2000). Geographical Information System in Health Service Research. D. P.

[3] Cromley, E. K., \& McLafferty, S. L. (2002). GIS and public health Guilford Press. New York.

[4] Dabhade, A., Kale, K.V. and Gedam, Y., (2015). Network Analysis for Finding Shortest Path in Hospital Information System. International Journal of Advanced Research in Computer Science and Software Engineering, Vol. 5(7), pp.618-623.

[5] Stefanakis, E. and Kavouras, M., (1995). On the determination of the optimum path in space. In: Proceedings of the European conference on spatial information theory, COSIT95, Lecture Notes in Computer Science ed. A. Frank and W. Kuhn Berlin: Springer-Verlag, pp. 241-257.

[6] Lokhman, M.T. and Rasam, A.R.A., (2012). Reforming health care facility using geographical information system. In 2012 IEEE Control and System Graduate Research Colloquium, IEEE, pp. 267-270.

[7] Peng, T. and Wang, X., (2012). A Mobile-based Navigation Web Application: Finding the Shortest-time Path based on Factor Analysis.

[8] Huang, K. and You, M., (2010). GIS-based environmental health management information system. In 2010 The 2nd Conference on Environmental Science and Information Application Technology, Vol. 3, pp. 85-87.

[9] P. Rai et al., (2013). Network Analysis Using GIS. International Journal of Emerging Technologies in Computational and Applied Sciences, Vol.5(3), June-August 2013, pp. 289292.

[10] Dijkstra, E.W., (1959). A note on two problems in connection with graphs. Numerische Mathematik, Vol.1, pp. 269-271.

[11] ESRI, (2015). Getting to know Arc GIS Desktop. ESRI, Redlands.

[12] Bhuvan, Indian Geo-Platform of Indian Space Research Organization (ISRO). http://bhuvan.nrsc.gov.in/bhuvan_links.php\#. Last accessed: 11th October 2020. 
[13] World population Prospects, 2020. https://population.un.org/wpp/

[14] DIVA GIS, 2020. https://www.diva-gis.org/. Last accessed: $1^{\text {st }}$ October, 2020.

\section{Author Contributions:}

M.B. Sushma carried out the study and the optimization process. Have also implemented the Algorithm in GIS platform.

Veera Reddy have been responsible for collecting the information for the case study.

The entire write up of the manuscript was taken care by both the authors, i.e., M.B. Sushma and Veera Reddy.

\section{Acknowledgment}

The authors would like to thank Kakatiya Institute of Technology and Science, Warangal for funding the project.

\section{Creative Commons Attribution License 4.0 (Attribution 4.0 International, CC BY 4.0)}

This article is published under the terms of the Creative Commons Attribution License 4.0

https://creativecommons.org/licenses/by/4.0/deed.en US 